\title{
LA LEGITIMIDAD DEL PRINCIPIO DISCURSIVO Y SU ENTRELAZAMIENTO CON LA FUNDAMENTACIÓN DE LOS DERECHOS FUNDAMENTALES. UN ANÁLISIS A PARTIR DE LA TEORIA HABERMASIANA*
}

\author{
Gerardo A. Durango Álvarez
}

\begin{abstract}
Resumen
El interés principal de este artículo es analizar la propuesta de fundamentación de los derechos fundamentales esbozada por Habermas a partir de la teoría de la acción comunicativa, de la democracia deliberativa y de la reconstrucción del derecho moderno que este autor propone desde el principio discursivo y el paradigma discursivo del derecho. Por consiguiente, la pretensión es la de explorar la conexión entre derechos fundamentales, espacios públicos formales e informales de participación y un modelo deliberativo de "democracia constitucional deliberativa" que Habermas establece a partir de varios de los supuestos y elementos que articulan su teoría de la acción comunicativa y, de un modo más preciso, su principio discursivo como búsqueda y fundamentación tanto de derechos como de espacios comunicativo-normativos.
\end{abstract}

Palabras clave: Principio discursivo - derechos fundamentales - validez de la norma.

\begin{abstract}
The main interest of this article is to analyze the proposal of foundation of the fundamental rights sketched by Habermas starting over the theory of the communicative action, of the deliberative democracy and of the reconstruction of the modern right that this author proposes from the beginning of discursive and the discursive paradigm of the law. Consequently, pretend to explore the connection among fundamental rights, formal and informal public spaces of participation and a deliberative model of 'deliberative constitutional democracy' that Habermas settles from several suppositions and elements that articulate its theory of the communicative action and, in a more precise way, its discursive principle as search and founding as much of right as communicative-normative spaces.
\end{abstract}

Key words: Discursive principle - fundamental rights - validity of the norm.

\footnotetext{
* En este artículo se esbozan algunas ideas desarrolladas en el Capítulo I del libro del autor: Derechos Fundamentales y Democracia Deliberativa. Temis/Universidad de Medellín, 2006.

**Doctor en Derecho por la Universidad Carlos III de Madrid - España. Maestría en Filosofía del Derecho por la Universidad Carlos III de Madrid. Profesor Investigador de la Universidad Nacional de Colombia, Sede Medellín.
} 


\section{Sumario}

1. Introducción. 2. Los derechos fundamentales en la teoría habermasiana y su relación con el principio discursivo. 3. Algunas críticas a la propuesta habermasiana del principio discursivo. 4 . Conclusiones.

\section{INTRODUCCIÓN}

Los derechos fundamentales presentan en la teoría habermasiana una doble dimensión: son, de una parte, condición de posibilidad de los espacios públicos democráticos, y de otra, construcciones o elaboraciones intersubjetivas de sujetos autónomos que se reconocen mutuamente libres e iguales en tanto autores de las normas -esto es, autolegisladores- y miembros de una comunidad jurídica. Esto posibilita el ejercicio de la autonomía privada y la autonomía pública de los individuos, como miembros activos de una comunidad jurídica, pues como afirma Habermas, sin democracia es muy difícil que exista Estado de Derecho. Según esta aseveración, la idea de autolegislación de los ciudadanos exige que aquellos que están sometidos al derecho, como destinatarios suyos, puedan entenderse, a la vez, como autores del derecho. Se sirve del principio del discurso y de su institucionalización jurídica en forma del principio democrático, para deducir desde allí la categoría de los derechos fundamentales.

El objetivo de este ensayo es analizar los planteamientos teóricos que expone Habermas para la fundamentación de los derechos fundamentales. Para ello se partirá de los planteamientos que éste realiza a partir de la teoría de la acción comunicativa, de la democracia deliberativa y de la reconstrucción del derecho moderno que este autor propone desde el principio discursivo y el paradigma discursivo del derecho.

Por consiguiente, la pretensión es la de explorar la conexión entre derechos fundamentales, espacios públicos formales e informales de participación y un modelo deliberativo de "democracia constitucional deliberativa" que Habermas establece a partir de varios de los supuestos y elementos que articulan su teoría de la acción comunicativa y, de un modo más preciso, su principio discursivo como búsqueda y fundamentación tanto de derechos como de espacios comunicativo-normativos. 


\section{LOSDERECHOSFUNDAMENTALESEN LATEORÍA HABERMASIANA Y SU RELACIÓN CON EL PRINCIPIO DISCURSIVO}

Los derechos fundamentales posibilitan en la teoría habermasiana el ejercicio ciudadano de la autonomía privada y la autonomía pública de los individuos, como miembros activos de una comunidad jurídica. En esta medida los derechos fundamentales, en cuanto condiciones de posibilidad, legitiman un orden jurídico y político y, a su vez, en cuanto construcciones, se fundamentan en la dinámica participativa y discursiva de los ciudadanos bajo condiciones de racionalidad e imparcialidad.

Esta doble dimensión de los derechos fundamentales lleva necesariamente a tomar en consideración dos aspectos centrales de la teoría de la acción comunicativa habermasiana: primero, los presupuestos de entendimiento derivados de las pretensiones de validez y segundo, los mecanismos procedimentales discursivos. En cuanto al primer aspecto, es de anotar que Habermas vincula éstas a su teoría de la acción comunicativa. Así, en una de sus definiciones expone que "la pretensión de validez de una norma consiste en su potencialidad para ser reconocida, lo cual tiene que demostrarse discursivamente; una norma válida merece reconocimiento porque, y en la medida en que, sea aceptada -es decir, reconocida como válida- también bajo condiciones de justificación ${ }^{-1}$ (aproximativamente) ideales". La validez ${ }^{2}$ en esta teoría incluye la acción normativa ligada a los acuerdos razonables ${ }^{3}$, lo cual supone no sólo la imposición coercitiva por parte del Estado, sino que incluye también la manera como aquella se liga a la legitimidad de las leyes propias del derecho moderno construida intersubjetivamente. Ello reviste la validez de una dimensión sustancial ${ }^{4}$-no solo formal-que obliga a redefinir y diferenciar los momentos de fundamentación y aplicación de dichas normas y, así mismo, a señalar como legítima la norma y el ordenamiento cuyos contenidos cuentan con los procedimientos jurídicos formales institucionalizados. De manera similar propone R. Alexy, su concepto de validez; la divide en tres categorías: la sociológica, relacionada con la eficacia social de las normas y su aceptabilidad racional por parte de los destinatarios; la ética, vinculada a las justificaciones morales o pretensión de corrección normativa, y la jurídica, que puede entenderse como aquellas disposiciones dictadas conforme a lo que prescribe la Constitución ${ }^{5}$.

La posibilidad de una fundamentación imparcial ${ }^{6}$ de normas que le sirva de referente para justificar los derechos fundamentales ha sido una constante por parte de Habermas ¿Pero cómo llega Habermas a tal concepción? Veamos; en conocimiento e interés, propone el conocimiento como orientador hacia el 
desarrollo de la autonomía y la libertad; esta última no viene dada como algo inmanente a la naturaleza del hombre -intuición abordada por Kant-, sino que es autorreflexiva y producto del intercambio entre los seres humanos; la autonomía tiene que ver con la simetría relacional que se establece entre los sujetos mediante el diálogo y las acciones comunicativas. En este sentido, el interés emancipatorio está intrínsecamente interrelacionado a la reflexión y por ende al lenguaje. En términos generales, se puede decir que el énfasis habermasiano se va a centrar en la apremiante necesidad de acceder a criterios normativos a partir de los cuales poder fundamentar una teoría social crítica. Mantener la necesidad de fundamentar dicha crítica, no significa para Habermas, que haya que renunciar a reivindicar su dimensión emancipativa social.

De esta manera, la búsqueda de criterios normativos que le sirvan de soporte al análisis social lleva a Habermas a preguntarse por la legitimidad, aproximándose de esta manera a problemas de legitimación del capitalismo tardío ${ }^{7}$, donde explica la crisis del capitalismo para dotarse de legitimación. En ella denuncia la contradicción insuperable entre la lógica manejada por el capital -que busca el interés privado- y las cuestiones normativas ínsitas en los procedimientos democráticos, lo que lleva a que el poder del Estado se imponga coactivamente y sin las bases necesarias para su justificación tanto democráticas como comunicativas. La dominación económica se ve en la necesidad de una legitimación controlada por el Estado que compense las disfunciones del mercado; pero el Estado se ve sobrecargado de las demandas sociales y sin posibilidad de atención, ocasionando una crisis de legitimación y que éste se oriente más por las cuestiones técnicas que por la realización de las normas práctico-morales y por la participación política real de los ciudadanos en su conformación. Ante tal situación, Habermas se inclina a plantear que el poder solo puede legitimarse, mediante discusiones públicas razonables en el cual los ciudadanos puedan contener el papel privatizador que ha adquirido el Estado. Se vale para ello del papel que cumple la moral y el derecho en la justificación de principios universales 8 .

De esta manera, la necesidad de conseguir un referente para su teoría racionalnormativa lo lleva a la teoría del lenguaje -giro lingüístico- y de ésta a su Teoría de la Acción Comunicativa. Con estos postulados ${ }^{9}$ comienza Habermas a replantear su teoría comunicativa como aquel espacio al que pueden recurrir los individuos para abordar los conflictos mediante acuerdos dialógicos. Sólo los sujetos capaces de lenguaje y acción pueden ser racionales. "Llamamos racional a una persona que se muestra dispuesta al entendimiento y que ante las perturbaciones de la comunicación se muestra reflexivo sobre las reglas 
lingüísticas"10. Para Habermas, la razón comunicativa no es una acción subjetiva asignada a un actor individual; por el contrario, la práctica comunicativa cotidiana proporciona el modelo de la racionalidad discursiva que, al mantener el debate dentro de los procedimientos discursivos, garantiza la imparcialidad de las normas.

Para justificar lo anterior, Habermas apela a la estructura dialógica del lenguaje como fundamento del conocimiento y de la acción, participando así de la corriente del denominado "giro lingüístico" en filosofía" ${ }^{11}$ Como resultado deduce la categoría de "acción comunicativa", donde la racionalidad está dada por la capacidad de entendimiento entre "sujetos capaces de lenguaje y acción" mediante actos de habla cuyo trasfondo es un "mundo de la vida" de creencias e intereses no explícitos y acríticamente aceptados por las comunidades de comunicación. La teoría de la acción comunicativa ${ }^{12}$, es para Habermas, el principio explicativo de una teoría de la sociedad fundada en una teoría del lenguaje y en el análisis de las estructuras generales de la acción, de allí que, el rasgo característico de los seres humanos será la racionalidad manifestada "objetivamente" en el "lenguaje". Como afirma Habermas, la acción comunicativa se apoya en un modelo que por así decirlo, está implícito desde el principio en el intento de establecer un entendimiento lingüístico. "La interacción lingüísticamente mediada exige el establecimiento de consenso y con la función de coordinar la acción mediada por normas. El entendimiento lingüístico funciona como mecanismo coordinador de la acción de modo que los participantes en la interacción se ponen de acuerdo sobre la validez que pretenden para sus actos de habla, es decir, se reconocen intersubjetivamente pretensiones de validez susceptibles de crítica"13. Por consiguiente, para Habermas lo que se convierte en objeto de examen discursivo no es la pretensión de rectitud directamente ligada al acto de habla, sino la pretensión de validez de la norma subyacente.

Los procesos argumentativos de dar razones mediante el lenguaje, no son ajenos a los procedimientos democráticos de seguir y aceptar normas y reglas. En este contexto es ilustrativo el asentimiento de A. Wellmer quien reitera que cuando argumentar a favor de una norma jurídica -o de un sistema de normas jurídicas- equivale a intentar demostrar, con razones y ante a cada uno de los afectados, porqué todas las personas razonables deberían poder juzgar como igualmente ventajoso para todos la vigencia social de una o varias de esas normas ${ }^{14}$. De esta forma, la pretensión de validez normativa busca que las afirmaciones o cuestionamientos realizadas por el hablante estén lo suficientemente bien fundamentadas racionalmente; una norma es correcta en estas circunstancias si ha sido el resultado de un proceso justificado 

derechos fundamentales, un análisis a partir de la Teoría Habermasiana

argumentativamente dentro de unas reglas generales del discurso y logrado mediante consenso argumentativo ${ }^{15}$.

De esta manera, la necesidad de repensar la discusión sobre las normas, la legitimidad normativa y el acuerdo racional que han de regir a los individuos, conduce a las primeras formulaciones que realiza Habermas sobre el principio discursivo ${ }^{16}$-referente mediante el cual fundamenta y deduce los derechos-. El carácter discursivo de validación de normas se encuentra abordado de la siguiente manera: "una norma sólo puede considerarse válida si pudiera encontrar el asentimiento en el círculo de los afectados bajo condiciones de una formación discursiva de la voluntad común ${ }^{17}$. Lo anterior significa que la esencia del lenguaje está establecida en su capacidad de lograr acuerdos normativos racionales, por conducto de acciones orientadas al entendimiento; este postulado le sirve a Habermas para introducir el principio discursivo de forma reflexiva, en cuanto los destinatarios de las normas pueden sentirse coautores de las mismas, convenciéndose unos a otros argumentativamente de que las normas y principios jurídicos y democráticos logrados por medios democráticos merecen ser reconocidas por todos los participantes.

Tal como fue expuesto por Habermas en teoría de la acción comunicativa -y en sus posteriores explicaciones-, el principio discursivo manifiesta, en su estructura, formas reflexivas de comunicación tendientes a introducir en el derecho moderno tanto de pretensiones de validez, provenientes de la acción comunicativa, como acciones dirigidas a la consecución de fines. Las pretensiones de validez deben producir por tanto en el derecho moderno, mecanismos de control para las acciones estratégicas. De esta manera, los procesos de discusión en los asuntos públicos elaborados con claras garantías para todos los afectados que han hecho parte en el "discurso práctico", deben posibilitar que todas las acciones relevantes vengan cubiertas por una doble faz: la coerción normal del derecho y la aceptabilidad racional de los afectados o amparados por dichas normas. De lo anterior se sigue que unos principios claros de "reglas de juego" hacen posible entendimientos menos violentos. Como dice García Amado, puesto que el consenso real puede ser fruto de la manipulación o coacción, la única manera de que tal reconocimiento pueda tener lugar de modo racional es arbitrando un procedimiento argumentativo en el que las partes expresen sus argumentos y contraargumentos ${ }^{18}$.

Conforme lo anterior, Habermas replantea nuevamente en "Facticidad y validez" el principio del discurso, que le servirá como referente al sistema democrático y jurídico de los estados democráticos de derecho. Lo expone de la siguiente manera: "válidas son todas las normas (y sólo aquellas normas) 
a las que todos los que puedan verse afectados por ellas pudiesen prestar su asentimiento como participantes en discursos racionales ${ }^{19 \prime \prime}$. Habermas pretende así, explicar el punto de vista desde el que pueden fundamentarse imparcialmente normas de acción. Este principio pretende dar cuenta de condiciones de simetría, en las cuales los ciudadanos puedan fundamentar, imparcialmente, las normas que intenten buscar el interés de todos por igual.

De esta manera el "principio del discurso" se aplica al principio democrático, el cual tiene como fin establecer las bases procedimentales por la cual los ciudadanos establecen las normas jurídicas que se presentan en forma de derecho. “De ahí que el principio democrático tenga no sólo que fijar un procedimiento de producción legítima de normas jurídicas, sino que tenga que regular y controlar también el propio medio que es el derecho" 20 . Analizada en esta perspectiva, el principio discursivo ha de interpretarse como un argumento racional que acoge concepciones pluralistas, pues al tener la capacidad de articular variados intereses particulares, éste se convierte en sustento teórico, a la vez que funciona como mecanismo reflexivo en la construcción y producción de normas legales y legítimas ${ }^{21}$. Lo que ha de entenderse como la necesidad de encontrar una teoría normativa lo más amplia posible, que logre entretejer lo institucional con la racionalidad discursiva, a modo de legitimar procedimientos legales.

El principio discursivo, al aplicarse a las normas jurídicas -deducido del principio general de acotación de las normas prácticas-, se convierte en "principio democrático". Habermas corrobora esto cuando declara: "El principio de discurso ha de empezar adoptando, por vía de institucionalización jurídica, la forma de un principio democrático, que proporcione a su vez al proceso de producción del derecho, fuerza generadora de legitimidad. La idea decisiva es que el principio democrático se debe al entrelazamiento del principio del discurso con la forma jurídica"22.

El principio jurídico establece que sólo tienen validez legítima aquellas normas jurídicas que pudiesen alcanzar el asentimiento de todos los miembros de una comunidad jurídica en un proceso de producción discursiva de esas normas jurídicas. Intenta Habermas de esta manera garantizar el sistema de los derechos y regular la integración social por medio de procedimientos jurídicos argumentativos $\mathrm{y}$, donde se posibilite, institucionalizar dichas prácticas, en aquellos espacios democráticos construidos en democrática forma y garantizados jurídicamente; esto es lo que le permite exponer la "génesis lógica de los derechos" y la fundamentación de éstos, como medios de autoorganización social. 


\section{ALGUNAS CRÍTICAS A LA PROPUESTA HABERMASIANA DEL PRINCIPIO DISCURSIVO}

Para Habermas ha sido complejo sostener sus primeras formulaciones del principio discursivo. Las críticas han provenido de diferentes frentes ${ }^{23}, \mathrm{y}$ dentro de éstas se encuentra Seyla Benhabib. Esta autora se sitúa dentro de la línea que ha venido replanteando la teoría crítica ${ }^{24}$; a partir de ésta retoma elementos normativos para analizar la ética comunicativa habermasiana y las teorías feministas; éstas, poco desarrolladas por las concepciones universalistas $\mathrm{y}$ formales de la primera, sostiene que en el principio discursivo existe un formalismo exagerado, manifiesto en la concepción de una razón legisladora universal -se basa la autora en las críticas lanzadas otrora por parte de Hegel a Kant- , que ha llevado a que se desconozcan los sujetos como participantes activos en los discursos fácticos, así como sus situaciones vitales. La igualdad de trato sólo tiene efectos reales cuando los sujetos cuentan con condiciones simétricas reales en sus relaciones, pues, de no ser así, la igualdad formal continuará perpetuando la desigualdad.

Propone reconstruir el principio de universalidad habermasiano, por permanecer insensible a los contextos sociales; ello ha llevado a que las personas no se comprometan con sus decisiones morales. Éste ha de darse en términos de una conversación continuada que se preocupe por un acuerdo racional o acuerdo general sobre prácticas normativas y relaciones morales en un estilo de vida concreto, esto es, el reconocimiento recíproco donde los participantes tienen alguna visión compartida, contextual entre un yo y un tú, lo que lleva a entender mejor la diferencia y los ámbitos privados de los que la ética discursiva se ha alejado ${ }^{25}$.

La autora recuerda a Habermas que los criterios de la racionalidad comunicativa han de provenir de los procesos de aprendizaje que pueden ser reconstruidos significativamente desde un universalismo contextualizado o interactivo -sensible a la narración- como gusta llamarlo. Lo que quiere decir Benhabib es que se hace necesario introducir, frente a los universalismos formales, una dimensión dialógica que escuche de igual manera a los "no oídos", a los "sin voz", a "los excluidos" y sobre todas aquellas concepciones que niegan nuestras "relaciones privadas" 26 . Por tanto, según Benhabib la universalización abstracta a la que tiende la teoría habermasiana, no debe desconocer la participación interactiva y contextualizada de los individuos en el aseguramiento de sus propias condiciones históricas. La universalización de la que parte las condiciones idealizadas del discurso -que protege los derechos de los individuos tanto en su autonomía y racionalidad-tendría 
que "situarse". Los consensos no se logran en perspectiva hipotética; son el resultado de intereses y de procesos de formación accesibles a los grupos e individuos en determinadas situaciones ${ }^{27}$. Habermas le responde que la "ética del discurso se refiere a aquellos presupuestos de la comunicación que cada uno de nosotros intuitivamente tiene que hacer, siempre que quiera participar seriamente en una argumentación" ${ }^{28}$. En "Aclaraciones a la ética del discurso", retoma Habermas los planteamientos de K. Günther para responder a la objeción de Benhabib, diciendo que "en el discurso de fundamentación -el que sigue la ética discursiva- solamente se prescinde de las inserciones contingentes en el contexto de una norma propuesta para que ésta última, en el caso que supere el test de universalización, esté suficientemente abierta a una aplicación sensible al contexto ${ }^{29 \prime \prime}$.

Esta "asimilación conceptual" que realiza Habermas entre moral y derecho es equívoca, en términos de Wellmer. Lo anterior le sirve para cuestionarle a Habermas el vincular a los fundamentos universales las pretensiones consensualistas de la verdad, así como las teorías de la moral y las teorías cognitivistas que, al confrontarse a casos particulares, encuentran serios problemas, "pues sólo la comunicación real me va a permitir comprobar hasta dónde llega mi comprensión de las apreciaciones ajenas, a través de una comunicación real entre las personas involucradas" ${ }^{\prime 30}$. Controvierte igualmente el hecho de que los autores no pueden participar infinitamente en el diálogo ${ }^{31}$, de ahí que al consenso infinito le esté vedada por principio una parte de esa verificación que tanto necesita para poder fungir como criterio de verdad ${ }^{32}$. Se refiere con lo anterior, a la categoría de verdad expuesta por Habermas como paradójica, por referirse a un supuesto ideal más allá de la necesidad del entendimiento lingüístico, que no puede satisfacer su objetivo fáctico comunicativo por exigir demasiado de las limitadas capacidades de la razón, ya que no todos los participantes en el diálogo poseen la misma oportunidad de "capacidad para el juicio moral"33. Por tanto, para Wellmer, en una comunidad ideal de comunicación como el planteado por Apel y Habermas, se niegan las condiciones de posibilidad real del diálogo, de allí que lo "contrafáctico" -recurso al que se acude de manera hipotética-, se convierte en un mecanismo que imposibilita que las condiciones del diálogo se den aquí y ahora como base de una acción comunicativa dialógica, libre y abierta. Ante esto puede decirse que lo que Habermas intenta es explicar el supuesto normativo e idealizado que emplea todo aquel que participa seriamente en una argumentación, de allí que proceda a "destrascendentalizar" la comunidad ideal de comunicación, explicándola como "situación ideal de habla", reteniendo para la misma el carácter idealizativo y regulativo necesarios para llegar a entendimientos acerca de las pretensiones de validez normativas; no 

derechos fundamentales, un análisis a partir de la Teoría Habermasiana

es, por lo tanto, un mecanismo que posibilite las condiciones del dialogo aquí $\mathrm{y}$ ahora, sino, un supuesto que ha de reconstruirse racionalmente y del que no podemos prescindir.

Con relación a la objeción -del excesivo paralelismo entre cuestiones morales y las proposiciones asertóricas ${ }^{34}$, Habermas ha respondido que la validez de los juicios morales se miden por la naturaleza inclusiva del acuerdo normativo al que llegan las partes en conflicto. Apela por consiguiente, a normas merecedoras de reconocimiento en el círculo de destinatarios de las mismas. Especifica que no se trata de concretar hechos, como sucede en el mundo objetivo, ya que en éste, la verdad de un enunciado depende de si el estado de cosas existe o no, mientras que en el mundo normativo el criterio de validez son las pretensiones que se derivan de éstas. El desempeño discursivo de una pretensión de verdad significa que las condiciones de verdad interpretadas como condiciones de asertabilidad están satisfechas, ya que -afirma Habermas- nos está vedado el acceso directo a condiciones de verdad no interpretadas. En el caso de las pretensiones de validez normativas el acuerdo alcanzado discursivamente fundamenta el reconocimiento de la norma correspondiente ${ }^{35}$.

En cuanto a la "situación ideal del habla", criticada por Wellmer, Habermas ha indicado la necesidad de mantener el contenido idealizador de los inevitables presupuestos pragmáticos de una praxis en la que, en idea, no deberían acabar imponiéndose sino los "mejores argumentos". Hay que interpretar el consenso habermasiano, como aquellos acuerdos referidos a los presupuestos comunicativos que se establecen cuando se recurre a pretensiones de validez. Las idealizaciones funcionan en este contexto como suposiciones anticipantes de una praxis que pretende que las acciones racionales de los individuos no desemboquen en acciones estratégicas ${ }^{36}$. Como afirma Habermas la práctica argumentativa se debe caracterizar por un procedimiento que, mediante la consideración racional de todas las voces, temas y aportaciones relevantes, pudiera dar cuenta de la trascendencia que, con respecto del contexto, tiene la verdad que el hablante pretende para su enunciado ${ }^{37}$. Las exigencias de simetría expuestas por la "situación ideal del habla", se deben entender como aquellas reivindicaciones que poseen los individuos y los grupos de poder participar en igualdad de condiciones en la toma de decisiones que les afectan, tanto en el procedimiento como en la evaluación de los resultados.

Frente a éstas $\operatorname{críticas}^{38}$, Habermas ha sostenido los siguientes puntos: en primer lugar, que si bien es cierto que los conflictos que ponen en juego valoraciones fuertes no parecen susceptibles de una solución consensual cuando cada cual 
los considera desde su propio punto de vista, es posible sin embargo hallar esa solución cuando se consideran las cosas desde un punto de vista moral. Como segundo, que la producción de normas se haya primariamente sujeta al punto de vista de la justicia y por este lado tiene su criterio primario de corrección en los principios que dicen qué es bueno para todos por igual. A diferencia de las cuestiones éticas, las cuestiones de justicia no están referidas de por sí a un determinado colectivo y a su forma de vida. El derecho políticamente establecido de una comunidad jurídica concreta, para ser legítimo, tiene que estar al menos en consonancia con principios morales, los cuales pretenden también validez general allende la comunidad jurídica concreta ${ }^{39}$.

Con lo anterior Habermas explica a McCarthy, que si quienes se involucran en una argumentación con el propósito de buscar solución a sus problemas no partieran del supuesto de que en principio es posible encontrar una solución correcta al problema en cuestión, "los participantes no tendrían ninguna idea de lo que están buscando", "las disputas políticas perderían su carácter deliberativo y degenerarían en luchas puramente estratégicas por el poder $^{40 \prime \prime}$. Es un supuesto del que tienen que partir quienes se involucran en una argumentación, ya sea que esta argumentación tenga lugar en el mundo de la vida o en las condiciones del procedimiento democrático, forma parte de las condiciones de sentido de la argumentación, es una posibilidad sin el cual la argumentación carecería de sentido como sostiene el propio Habermas en su réplica a McCarthy.

\section{CONCLUSIONES}

Las críticas anteriores al principio discursivo, así como la explicación que sobre éste ha realizado Habermas a partir de las diferentes sugerencias recibidas por parte de defensores y contradictores, han influido para que Habermas reconsiderara su planteamiento inicial con algunas matizaciones significativas tales como:

1. La teoría del discurso ha aprendido la lección y distingue entre validez -o la justicia- de las normas y la corrección de los juicios singulares ${ }^{41}$.

2. Habermas ha complementado las normas y principios generales fundamentadas en el procedimiento democrático -principio de fundamentación, con el principio de adecuación -la aplicación de la norma al caso concreto y el análisis de todas las circunstancias, permiten al juez poner de manifiesto posibles inconsistencias en el momento de la fundamentación de las normas y advertir cómo se podrían corregir, pues éste, al aplicar el 

derechos fundamentales, un análisis a partir de la Teoría Habermasiana

derecho, corrobora o no la imparcialidad de la norma- a contextos plurales, con el fin de validar relaciones de reconocimiento recíproco.

3. El principio discursivo puede entenderse como aquél juicio reflexivo por medio del cual los individuos y grupos pueden acordar normas producidas mediante razones válidas para todos los afectados.

4. Los principios y normas generales se deben aplicar de manera "imparcial" al contexto desde los diferentes planos argumentativos tales como: el ético (encargado de las identidades en las que se hayan inmersos los ciudadanos), democrático (regla básica del reconocimiento recíproco de los participantes en discursos racionales) y jurídico (conjunto de normas institucionalizadas que han contado con el asentimiento de todos los afectados). Lo que es respuesta a la crítica de Wellmer. Las reglas de la argumentación aportan elementos relevantes tanto para la fundamentación como para la aplicación de normas. "Nadie será excluido de la discusión", "que se escuche a todos los implicados", "se debe argumentar racionalmente", "serán tenidas presentes las argumentaciones dadas mediante la coacción de los buenos argumentos". Tales reglas son ejemplos de que funcionan como ideal regulativo a seguir por aquellas instituciones -sociedades- que deseen comparar sus prácticas con situaciones o acciones que se habrían tomado bajo otros mecanismos: sirven para analizar qué grado de acuerdos, desviación o desacuerdos, en lo moral, ético, político o jurídico presentan actualmente las instituciones democráticas.

5. Si bien el principio discursivo no se presenta como mecanismo de acción comprobable en la práctica, sí se erige como aquella concepción moral, política y jurídica que pretende conseguir un marco público lo más amplio posible, donde tenga cabida la manifestación de diversas concepciones y expresiones racionales. El principio discursivo posibilita no sólo a los ciudadanos, sino también al legislador y al juez, decidir si en la justificación y aplicación de los derechos fundamentales se han ofrecido todas las garantías democráticas existentes. Como teoría pretende dar cuenta de los diversos acuerdos y desacuerdos de la razón práctica -razones comunicativas en términos habermasianos-, es decir, funciona como criterio de reflexión pública, mediante pretensiones de corrección.

6. El principio discursivo permitecriticary repensar aquellos estados de derecho que históricamente han utilizado solo la coacción en sus decisiones políticas y jurídicas. Ello debe posibilitar replantear aquellas instituciones que, como la colombiana, han tenido muy poco en cuenta el componente comunicativo en 
La legitimidad del principio discursivo y su entrelazamiento con la fundamentación de los derechos fundamentales, un análisis a partir de la Teoría Habermasiana

su quehacer político y en la forma de entender el conflicto social que se vive en estos momentos. Como apunta Alexy: "Especial importancia tiene el hecho de que la pretensión de corrección no sea abandonada con la transferencia de la decisión a procedimientos jurídicos. De allí se sigue la necesidad de institucionalizar la fundamentación y la crítica en los procedimientos jurídicos y fuera de ellos garantizarlos iusfundamentalmente. La teoría del discurso resulta ser así una teoría básica del Estado Constitucional Democrático que apunta a la discusión ${ }^{42 "}$.

La acción comunicativa resulta, de esta manera, especialmente relevante para la búsqueda de la integración social en aquellas sociedades donde el componente conflictivo es demasiado alto y excluyente. Ahora bien, la comunicación no es la panacea para todos los males, pues a medida que se avanza en la evolución social, aumenta la posibilidad del disenso en la comunicación, porque va operando internamente en la sociedad una creciente diferenciación entre los individuos y la "pluralización de las formas de vida" que generan una constante y permanente tensión entre los intereses particulares y el conjunto de formas de vida, que pretenden universalizar determinadas condiciones de convivencia. Por tanto, la acción estratégica será deudora, de una u otra manera, de las comprensiones básicas de la convivencia social, pues ésta no puede dirigir las interacciones sociales sólo en las acciones tendientes al cálculo y a las expectativas individuales.

Desde esta perspectiva, el paso que da a continuación Habermas, consiste en acercar su propuesta teórica del principio discursivo al Estado Democrático de Derecho con el fin de institucionalizar los derechos fundamentales deducidos de su propuesta teórica del principio discursivo. Pero por cuestiones deespacio se debe dejar por ahora planteada tal cuestión para un próximo ensayo.

1 Habermas, J. Verdad y justificación. Trotta, 2002. Pág. 53. Habermas entiende por justificación, aquellas condiciones de aceptabilidad de las razones que prestan a las legitimaciones eficacia, fuerza consensual y fuerza motivadora. Habermas, J. La reconstrucción del materialismo histórico. Madrid: Taurus, 1985. Pág. 251. De forma similar S. Benhabib ha dicho que "las bases de la legitimidad en las instituciones democráticas se deben trazar en la presunción de que las instancias que demandan el cumplimiento de obligaciones lo hacen porque sus decisiones corresponden a un punto de vista imparcial que es igualitario respecto a todos. Esta presunción sólo puede ser satisfecha si es que estas decisiones están abiertas a un proceso público de deliberación por ciudadanos libres e iguales. Benhabib, S. "Toward a deliberative model of democratic legitimacy". En: Democracy \& Difference. Princeton University Press, 1996. Pág. 68.

2 En el campo jurídico, el concepto de validez se encuentra saturado de significados y emparentado con conceptos como vigencia, eficacia y justicia. La validez se refiere a la coherencia del contenido de las normas con relación a las determinaciones establecidas en niveles superiores del ordenamiento que en virtud de la inserción de principios y valores, hacen que dichos juicios sean complejos, jurídicos e internos 

derechos fundamentales, un análisis a partir de la Teoría Habermasiana

al ordenamiento. Las demás demarcaciones no serán acometidas acá por cuestiones metodológicas. El objetivo de este trabajo no es realizar una descripción sobre cada uno de estos conceptos. Ello desbordaría las pretensiones de la investigación. Existe amplía bibliografía al respecto. Ver: Alexy, R. El concepto y la validez del derecho. -En especial el capítulo III-. Gedisa, 1997. Peña Freire, A. La garantía en el Estado constitucional de derecho. Trotta, 1997. Böckenförde, E. Estudios sobre el Estado de Derecho y la Democracia. Tradución de Rafael de Agapito Serrano. Trotta, 2000. R, Guastini. Distinguiendo: Estudios de Teoría y Metateoría del Derecho. Barcelona: Gedisa, 1999. Ferrajoli, L. Derechos y Garantías: La ley del más débil. 2da. Edición. Madrid: Trotta, 2001. José Luis Serrano. Validez y Vigencia. Trotta, 1999.

3 En Teoría de la acción comunicativa había dicho Habermas que una pretensión de validez es un potencial de razones que poseen los hablantes en un diálogo con el fin de aprobar o rechazar un enunciado. Las razones interpretan las condiciones de validez y pertenecen, por tanto, ellas mismas, a las condiciones que hacen aceptable una emisión. Habermas, J. Teoría de la acción comunicativa. T.I Taurus, 1987. Pág. 342.

4 Para Ferrajoli, el garantismo representa la otra cara del constitucionalismo, en especial aquella que se encarga de "formular las técnicas de garantía idóneas para asegurar el máximo grado de efectividad de los derechos reconocidos constitucionalmente". Ferrajoli. Iuspositivismo crítico y democracia constitucional. En: Revista Isonomía 16, 2002. Pág. 16. El garantismo está al servicio de los derechos fundamentales, tanto en su dimensión formal como sustancial. Indica quien manda, qué se manda y como se manda. Como afirma Ferrajoli: "para que una ley sea válida es además necesaria la coherencia de sus significados con las reglas y principios que bien podemos llamar normas sustanciales sobre la producción". Ver al respecto: "Sobre la definición de democracia. Una discusión con M. Bovero". En: Revista Isonomía 19, 2003. Pág. 230.

5 Alexy, R. El concepto y validez de derechos. Gedisa, 1997. Pág. 87. La pretensión de corrección de Alexy es deudora de la ética discursiva expuesta por Habermas, al decir de Touri: "Según la teoría jurídico éticodiscursiva, sólo aquellas normas y juicios jurídicos que puedan satisfacer las pretensiones de corrección, esto es, que puedan ser aceptadas en discursos práctico-morales pueden considerarse legítimos en el sentido normativo del término". Kaarlo Touri, "Etica discursiva y legitimidad del derecho". Revista Doxa, Nro. 5, 1988. Pág. 48.

6 En: Aclaraciones a la Ética del discurso. Trotta, 2000. Habermas afirma que: "La idea de imparcialidad sólo se agota cuando andan juntos dos principios, el de universalización y el de adecuación y sólo sí el principio de universalización en los discursos de fundamentación es asumido por el principio de adecuación ". Pág. 147. Es en ese espacio de fundamentación donde aquellas normas se justifican y pueden aplicarse al caso concreto.

7 Habermas, J. Problemas de legitimación del capitalismo tardío. Buenos Aires: Amorrortu, 1975.

8 Ibíd. Pág. 156. La pretensión de rectitud normativa funciona como garante ilocucionario de los intereses generalizables en las prácticas comunicativas, ello -a mi modo de ver- sirve de base para que Habermas reacomode su teoría comunicativa hacia el universalismo moral; soporte esencial del principio discursivo.

9 Habermas se inscribe teóricamente en las propuestas del contrato social de Rousseau, del proyecto de eticidad de Hegel y del imperativo categórico de Kant, entre otras. Al respecto S. Benhabib, afirma que, siguiendo las huellas del imperativo categórico de Kant, el modelo procedimental de una práctica argumentativa reemplaza el silenciosoexperimento-pensanteque sigue la idea kantiana de la universalidad. Benhabib, S. Situating the Self. Gender Community and Postmodernism. In: Contemporary Ethics, New York: Routledge, 1992. Pág. 24.

10 Habermas, J. Teoría de la acción comunicativa... Op.cit. Pág. 42.

11 En este sentido ver. Lafont, C. La razón como lenguaje. Madrid: Visor, 1993 y una versión ampliada en The linguistic tur in hermeneutic philosophy. Cambridge, Mass, 1999.

12 En las páginas finales de Teoría de la acción comunicativa -segundo tomo- Habermas manifiesta que el propósito de su investigación era introducir la teoría de la acción comunicativa para dar razón de los fundamentos normativos de una teoría crítica de la sociedad. Es crítica por cuanto busca afirmar la racionalidad y la autor reflexividad de las prácticas comunicativas en busca de la obtención de consensos. Teoría de la acción comunicativa, es además, el marco teórico para el proyecto de análisis y de estudios interdisciplinarios sobre la racionalización capitalista moderna desde una perspectiva filosófica.

13 Habermas, J. Teoría de la Acción Comunicativa T. II. Taurus, 1987. Pág. 482.

14 Wellmer. Ética y diálogo. Anthropos, 1994. Prólogo de María Pía Lara. Pág. 105.

15 Alexy. R. La pretensión de corrección del derecho. La polémica Alexy/Bulygyn sobre la relación entre derecho y moral. Universidad externado de Colombia, 2001. Pág. 27. Alexy propone una pretensión de corrección justa desde una adecuación a la fundamentación normativa y a la moralidad crítica introducida en el ordenamiento por medio de los procedimientos democráticos. 
16 La validez y aceptación de las normas por parte de los afectados, premisa fundamental de la que parte el principio discursivo, puede ser abordado de dos maneras: 1) si las normas válidas pueden recibir su aceptación por parte de todos los afectados en cuanto a su condición de personas morales, como ser que tiene dignidad y por tanto merece respeto y, 2) desde la validez de las normas y su aceptación por parte de los afectados en cuanto condiciones que posibilitan la autonomía privada y pública, la construcción del Estado Democrático de Derecho y los derechos fundamentales. Si bien la segunda no excluye la primera, no se retomará el camino desarrollado por la teoría moral. Con relación a la validez jurídica del Estado Democrático de Derecho, éste tiene un doble rostro: por un lado cumple funciones estratégico-sistémicas y por otro busca integrar socialmente a la ciudadanía en su conjunto a través de la soberanía popular procedimentalizada discursivamente mediante el catalogo de derechos fundamentales; éstos garantizan su legitimidad política y propician su validez jurídica.

17 Habermas, J. Teoría de la acción comunicativa: Complementos y estudios previos. Cátedra, 1989. Pág. 432.

18 García Amado, J. La filosofía del derecho en Habermas y Luhmann. Universidad Externado de Colombia, 1997. Pág. 74.

19 Habermas, J. Facticidad y Validez. Sobre el derecho y el estado democrático de derecho en términos de teoría del discurso. Trotta, 1998. Pág. 172. En el planteamiento de McCarthy el principio discursivo se puede entender conforme la pregunta que este autor realiza sobre la imparcialidad: ¿Cómo podemos esperar de forma razonable, llegar a acuerdos universales sobre la aceptabilidad de las consecuencias de una norma para la satisfacción legítima de necesidades, en una sociedad pluralista? Thomas McCarthy. Ideales e ilusiones. Técnos, 1992. Pág. 195.

20 Habermas, J. Facticidad y Validez... Op.cit. Pág. 176. Conforme al principio discursivo, el procedimiento de producción legítimo de normas se operativiza de acuerdo con las cuestiones discursivas que trate: moral, ética, jurídica o pragmática.

21 Otra de las relaciones que se pueden establecer entre el principio discursivo y la concepción de los derechos fundamentales en la teoría habermasiana, se podría formular a partir del interrogante: ¿Cómo se pueden institucionalizar las pretensiones comunicativas del principio del discurso de tal forma que se integren desde la autonomía privada y la soberanía popular las normas de convivencia que tendrían que poder asentir todos los afectados por la misma y, al mismo tiempo, ser coautores de sus derechos? El intentar responder este interrogante lleva a Habermas a proponer cuatro rasgos básicos que posee la estructura de cualquier argumentación, supuesto un proceso discursivo orientado al entendimiento; discursos que de hecho sostenemos diariamente:

1. Nadie que pueda hacer una contribución relevante, debe ser excluido de la participación.

2. A todos se les dan las mismas oportunidades de hacer sus aportes.

3. El sentido de los juicios de validez ha de tener carácter general.

4. La posibilidad de distinguir cognitivamente entre juicios morales correctos e incorrectos.

5. La comunicación tiene que estar libre de coacciones, tanto internas como externas, susceptibles de crítica y motivadas por la fuerza de convicción del mejor argumento. Ver Habermas, J. La Inclusión del otro, Estudios de teoría política. Paidós, 1999. Pág. 76. Alexy expone de forma similar al planteamiento habermasiano, sus reglas de tipo no-monológicas. "Una norma puede encontrar aprobación universal en un discurso sólo si las consecuencias de su cumplimiento general para la satisfacción de los intereses de cada individuo pueden ser aceptadas por todos sobre la base de argumentos". Alexy, R. El concepto y la validez del derecho... Op.cit. Pág. 138.

22 Ibíd. Pág. 187.

23 Existe una extensa bibliografía al respecto. Ver: A. Cortina. Ética sin moral. Tecnos, 1992. Javier Muguerza. Desde la perplejidad. (Ensayos sobre la ética, la razón y el diálogo) F.C.E, 1990. Th. McCarthy. La teoría crítica de Jürgen Habermas. Tecnos, 1987. A. Giddens y otros. En: Habermas y la modernidad. Cátedra, 1998. A. Welmer. Ética y diálogo. Anthopos, 1994.

24 Benhabib, S. Critique, Norm and Utopia. New York, Columbia University Press, 1986.

25 Benhabib S. Situating the Self. Gender Community and Postmodernism. En: Contemporary Ethics. New York: Routledge, 1992. Pág. 38. Esta obra aborda varios temas tales como: el universalismo, la política moral, el proyecto de la modernidad, la crítica a las teorías de la justicia, etcétera.

26 Ibíd. Pág. 163. Una propuesta que se acerca a la teoría de S. Benhabib y Th. McCarthy es la de E. Dussel. Este autor critica igualmente el formalismo de la ética del discurso. Expresa: "Habermas se ocupa largamente de la fundamentación del "único" principio formal de la Ética del Discurso. La ignorancia del principio material de la ética imposibilita el descubrir éticamente la imposibilidad de la reproducción y el desarrollo de la vida de cada sujeto humano en comunidad en este o aquel sistema ético concreto". Dussel, E. Ética de la liberación. Trotta, 2000. Pág, 199. Propone como superación de la ética discursiva habemasiana, su ética 


\section{Gerardo A. Durango Álvarez \\ La legitimidad del principio discursivo y su entrelazamiento con la fundamentación de los derechos fundamentales, un análisis a partir de la Teoría Habermasiana}

de liberación; para ésta, los enunciados normativos pueden ser evaluativos (con pretensión de rectitud en su contenido material de valor), éticos en sentido fuerte (con pretensión de verdad práctica), o meramente morales (con pretensiones de de validez moral). Ibíd. Pág. 196. Dussel pretende corregir la ética discursiva, desde la no primacía entre lo moralmente obligatorio sobre lo que es éticamente deseable o preferible. Le apuesta a lo que denomina "co-determinaciones sin primacías", ibídem.

Benhabib S. Situating the Self. Gender Community and Postmodernism..., Op.cit. Pág. 221.

28 Habermas, J. Teoría de la acción comunicativa: complementos y estudios previos... Op. Cit. Pág. 442.

29 Habermas, J. Aclaraciones a la ética del discurso... Op.cit. Pág. 170.

30 Wellmer, A. Etica y diálogo. Anthropos, 1994. Pág. 72. En este textoaborda el au tor, problemas concernientes a las éticas kantianas, del juicio moral, la relación entre validez y fundamentación de la ética, la ética dialógica, etcétera.

31 Esta es una crítica esbozada por Wellmer a la manera en que Habermas acude a Pierce, esto es, como cuando dice que: el consenso es el resultado "ideal" de un potencial acuerdo que se alcanzará el final de todos los razonamientos. Wellmer lo considera irreal.

32 Ibíd. Pág. 233. Wellmer critica que Habermas utilice la idea del consenso, para justificar las teorías de la verdad y las teorías normativas. Si no se llega a los consensos, no por ello se infiere irracionalidad. Ibíd. Pág. 78. Una crítica similar a la expuesta por Wellmer sostiene E. Tugendhat en "Problemas de ética", Crítica, 1988. En ésta, acentúa el componente "voluntad" -la comunicación no presenta un carácter cognitivo como sugiere Habermas en su teoría ética, sino que posee un carácter volitivo como capacidad de decisión individual- en la definición de lo moralmente correcto. Con ello quiere señalar la insuficiencia habermasiana de escorar, primero, las cuestiones morales a las cuestiones doxásticas (verdad), y a la "concreción" de las decisiones morales que se escapan del marco discursivo, en segundo lugar. Critica igualmente a Habermas el convertir el consenso en criterio de verdad y en base de la justificación racional, lo que lleva a que las condiciones ideales no se ajusten a las condiciones reales. Ibíd. Págs. 125-127. En: Lecciones de ética. Gedisa, 1997. Tugendhat prepone una moral de respeto y estima recíproca sustentado en su idea de la "autodeterminación"; base del reconocimiento moral de otro. Aportar razones en pro o en contra de una decisión tomada, permite romper la circularidad a la que conlleva la teoría habermasiana de la situación ideal del habla. Ibíd. Pág. 145 y 161. Nótese la similitud de la crítica con la expuesta por Benhabib y Wellmer. Habermas ha respondido a la crítica de Tugendhat diciendo que "ciertamente, no nos es lícito equiparar sin más las convicciones morales al saber epistémico, pues las primeras nos dicen qué debemos hacer, mientras que sólo conocemos algo en sentido estricto cuando sabemos como se las han las cosas. Pero de ahí no se sigue que el saber cotidiano dominado intuitivamente no constituya saber alguno". Habermas, Aclaraciones a la ética del discurso... Op.cit. Pág. 128. Habermas rechaza igualmente de Tugendhat, el que pretenda fundamentar pragmáticamente sólo el uso práctico de razón, y dejar para los enunciados susceptibles de verdad el concepto semántico. Dice Habermas que Tugendhat fundamenta la primera desde una perspectiva interna, lo que lleva a que los individuos acepten la moral egocéntrica. "Los juicios morales y las normas pierden su sentido ilocutivo en la medida en que sólo pueden aspirar entonces a una validez relativa, es decir, a una validez que depende del resultado de una reflexión instrumental" La verdad y la falibilidad son dos caras de la misma moneda. Habermas, Verdad y justificación... Op. cit. Pág. 266.

33 Acá habría que cuestionarle a Wellmer su escepticismo para con aquellos que no pueden participar en el diálogo; pues a lo que invita la teoría habermasiana es a que se abran aquellos espacios obstaculizados para que todos los afectados puedan participar en igualdad de condiciones y $\sin$ obstrucciones. Cuando existen espacios cerrados para el diálogo, se está condicionando instrumentalmente a los que desean participar en él. Al respecto Habermas ha dicho que el discurso práctico exige la inclusión de todos los intereses de los afectados en cada caso y se extiende incluso a un examen crítico de las interpretaciones que nos permiten percibir determinadas necesidades como intereses propios. Ver al respecto, Escritos sobre moralidad y eticidad. Paidós, 1991. Pág. 118.

34 Ibíd. Pág. 246. En otra perspectiva de la discusión, C. Lafont le critica a Habermas el pretender fundamentar la corrección normativa mediante concepciones epistémicas de verdad. Plantea que tiene que haber un elemento realista en las cuestiones morales -como las hay en las cuestiones de hecho en torno a la idea de verdad-. Las cuestiones sobre lo correcto o justo también refieren a "hechos", pero el que un enunciado sea de facto en igual interés de todos -eso es lo que suponemos cuando decimos que algo es justo-, no equivale a que discursivamente todos estemos de acuerdo en ello -podemos estar equivocados al respecto-. Lafont propone que se debe incorporar el falibilismo por igual en las cuestiones morales y en las de hecho. Con lo anterior, critica a Habermas el reducir la pretensión de validez (verdad, corrección) a acuerdos discursivos. C. Lafont La verdad como lenguaje. Visor, 1993. Pág. 245. Señala, igualmente, lo paradógico de un saber aceptado como condición ideal, pues al negársele su carácter falible o de ser complementado o mejorado, 


\section{Gerardo A. Durango Álvarez \\ La legitimidad del principio discursivo y su entrelazamiento con la fundamentación de los derechos fundamentales, un análisis a partir de la Teoría Habermasiana}

perdería su "conexión con capacidades humanas". Lafont, Dilemas en torno a la verdad. En: Revista Theoría, Nro. 23, 1995. Pág. 113. Si bien, en Verdad y justificación, Habermas acepta que en cuestiones de hecho la pretensión de verdad refiere también a una intuición realista -acepta parcialmente la crítica de Lafont-, no piensa que para las cuestiones normativas sea lo mismo. La razón práctica como acuerdo discursivo, conforma la idea misma de corrección. Habermas le ha respondido igualmente diciendo que el sentido crítico de la orientación de la verdad como una idea regulativa resulta claro precisamente cuando se idealizan las propiedades formales o procesuales de la argumentación, no sus objetivos. El desempeño discursivo de una pretensión de verdad significa que las condiciones de verdad interpretadas como condiciones de asertabilidad están satisfechas, de allí que concluya afirmando que en la teoría discursiva de la verdad, un enunciado es verdadero si, bajo las exigentes condiciones de un discurso racional, puede resistir todos los intentos de refutación mediante razones. Confirma aún más lo anterior cuando señala que: "los mandatos morales no se refieren a algo en el mundo objetivo tal y como lo hacen las expresiones constatativas, y sin embargo, al igual que éstas últimas sí que se refieren a algo objetivo. Lo debido no es ni una mera entidad ni una mera vivencia". Aclaraciones a la ética del discurso... Op.cit. Pág. 135. En el texto Verdad y justificación, menciona que "la argumentación continúa siendo el único medio disponible para cerciorarse de la verdad, ya que las pretensiones de verdad que devienen problemáticas no pueden examinarse de otra forma". Habemas, J. Verdad y justificación. Trotta, 2002. Pág. 50.

35 Ibíd. Pág. 254

36 Para Habermas, la acción estratégica es insuficiente para lograr acuerdos perdurables socialmente. Es oportuno traer a colación la crítica que esgrime Prieto Navarro -siguiendo a McCarthy-a la diferenciación entre acción estratégica y acción comunicativa expuesta por Habermas, al respecto dice " ni todas las interacciones mediadas por el lenguaje son acciones comunicativas, ni todas las interacciones estratégicas operan con abstracción del elemento consensual contenido en el habla racional". Evaristo, Prieto Navarro, Jürgen Habermas: acción comunicativa e identidad política, CEC, 2003. Pág 58. La crítica es válida a medias, pues en Facticidad y validez, la dicotomía no es tan radical como en Teoría de la acción comunicativa. Habermas, J. Verdad y justificación... Op. cit. Pág. 49. Habermas es consciente -acepla las críticas de Wellmer y Lafont- de que el nexo conceptual entre verdad y la asertabilidad racional, no comporta una relación defendible en condiciones ideales, ya que las razones pragmáticamente "irresistibles" no son, en el sentido lógico de la validez definitiva, razones "imperativas" o concluyentes. Ibíd. Pág. 49. Reitera sin embargo que el nexo conceptual irrebasable no puede ofrecerse como un nexo conceptualmente indisoluble. La corrección sigue siendo por tanto para Habermas un "concepto" epistémico que funciona como pauta interpretativa para aquellas pretensiones de validez socialmente reconocidas.

37 Habermas, I. Verdad y justificación... Op. cit. Pág. 49. Habermas es consciente -acepta las críticas de Wellmer y Lafont- de que el nexo conceptual entre verdad y la asertabilidad racional, no comporta una relación defendible en condiciones ideales, ya que las razones pragmáticamente "irresistibles" no son, en el sentido lógico de la validez definitiva, razones "imperativas" o concluyentes. Ibíd. Pág. 49. Reitera sin embargo que el nexo conceptual irrebasable no puede ofrecerse como un nexo conceptualmente indisoluble. La corrección sigue siendo por tanto para Habermas un "concepto" epistémico que funciona como pauta interpretativa para aquellas pretensiones de validez socialmente reconocidas.

38 Habermas, "Reply to symposium participants, Benjamin N. Cardozo School of Law". En Arato, Andrew and Rosenfeld, Michael (eds). Habermas on Law and Democracy: Critical Exchanges. Berkeley, California University Press, 1998.

39 Ibíd. Pág. 398

40 Tbíd. Pág. 396. Igualmente menciona en este sentido que, "La política deliberativa perdería su sentido y la democracia constitucional perdería su base de legitimidad si los participantes en discursos políticos no quisieran convencerse mutuamente y aprender unos de los otros. Las disputas políticas perderían su carácter deliberativo y degenerarían en luchas puramente estratégicas por el poder si los participantes no asumieran sin duda, falibilísticamente, conscientes de que siempre pueden estar equivocados que las controversias políticas y los problemas jurídicos tienen una solución correcta. Si no se orientaran hacia el objetivo de resolver problemas dando razones, los participantes no tendrían ninguna idea de lo que están buscando." Ibíd. Pág. 394.

Ibíd. Pág. 145.

41 Ibíd. Pág. 145

42 Alexy, R. El concepto y la validez del derecho... Op. cit. Pág. 157. 